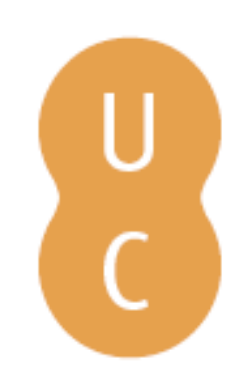

\title{
nombalina
}

\section{Licenciamento em águas públicas e cartografia: o caso do Rio Ave no início do século XX}

\author{
Autor(es): $\quad$ Costa, Francisco da Silva \\ Publicado por: Imprensa da Universidade de Coimbra \\ URL \\ persistente: URI:http://hdl.handle.net/10316.2/31155 \\ DOI: $\quad$ DOI:http://dx.doi.org/10.14195/978-989-26-0244-8_67 \\ Accessed : $\quad$ 26-Apr-2023 11:05:58
}

A navegação consulta e descarregamento dos títulos inseridos nas Bibliotecas Digitais UC Digitalis, UC Pombalina e UC Impactum, pressupõem a aceitação plena e sem reservas dos Termos e Condições de Uso destas Bibliotecas Digitais, disponíveis em https://digitalis.uc.pt/pt-pt/termos.

Conforme exposto nos referidos Termos e Condições de Uso, o descarregamento de títulos de acesso restrito requer uma licença válida de autorização devendo o utilizador aceder ao(s) documento(s) a partir de um endereço de IP da instituição detentora da supramencionada licença.

Ao utilizador é apenas permitido o descarregamento para uso pessoal, pelo que o emprego do(s) título(s) descarregado(s) para outro fim, designadamente comercial, carece de autorização do respetivo autor ou editor da obra.

Na medida em que todas as obras da UC Digitalis se encontram protegidas pelo Código do Direito de Autor e Direitos Conexos e demais legislação aplicável, toda a cópia, parcial ou total, deste documento, nos casos em que é legalmente admitida, deverá conter ou fazer-se acompanhar por este aviso.

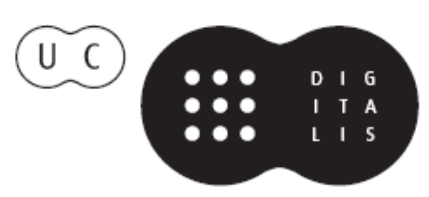




\section{TRUNFOS DE UMA}

\section{EOGRAFIA ACIVA}

\section{DESENVOLVIMENTO LOCAL,}

AMBIENTE,

ORDENAMENTO

E TECNOLOGIA

Norberto Santos

Lúcio Cunha

COORDENAÇÃO 


\section{LICENCIAMENTO EM ÁGUAS PÚBLICAS E CARTOGRAFIA \\ O CASO DO RIO AVE NO INÍCIO DO SÉCULO XX}

\section{Metodologia}

O trabalho de pesquisa e investigação que sustenta este artigo decorreu no Arquivo da Administração da Regiāo Hidrográfica do Norte, onde foram consultados 23249 processos do Domínio Público Hídrico na bacia hidrográfica do rio Ave, relativos ao período 1902-1973.

A quase totalidade dos processos consultados (87\%) é referente a licenciamento, sendo constituída, essencialmente, por requerimentos ligados ao uso das águas públicas e à ocupação do Domínio Público Hídrico.

A metodologia de trabalho obedeceu às seguintes fases:

1. leitura dos processos;

2. transcrição dos principais documentos;

3. digitalização de cartografia, esquemas, plantas e projectos;

4. análise dos elementos recolhidos.

Várias dificuldades surgiram na análise dos processos existentes:

- enganos, confusóes e omissóes nas referências geográficas, quer administrativas (freguesias e concelhos), quer físicas (nomes dos cursos de água) dos pedidos efectuados; procedeu-se, neste caso, a um exercício de comparação e cruzamento com elementos de outros processos, principalmente, com base no nome do requerente ou do lugar;

- o desdobramento de designaçóes utilizadas para os mesmos cursos de água - Inicialmente foram contabilizados 1465 cursos de água que depois de validados passaram para 1097. Esta discrepância resulta essencialmente das diferentes designaçóes atribuídas pelos sucessivos guarda-rios dos mesmos cantóes, bem como dos requerentes aquando da entrega dos pedidos;

- a falta de alguns elementos nos documentos consultados, principalmente a escala e a orientação, nos projectos apresentados.

\section{QUADRO NORMATIVO E REGULAMENTAR}

A administração hidráulica foi instalada em Portugal no final do século XIX, com a publicação em 1892 do Regulamento dos Serviços Hidráulicos (RSH) que, pela primeira vez no nosso país, vem definir um quadro legal coerente para a gestáo da água. 
A orgânica de cada secção está definida pelos artigos $43^{\circ}$ ao $48^{\circ}$, onde são referidas de forma hierarquizada, as atribuiçóes e competências, de carácter mais executivas, para o director da circunscrição hidráulica e os engenheiros chefes das secçóes do serviço externo, e mais administrativas e técnicas, dos restante pessoal, nomeadamente do chefe de secção, dos mestres de valas e dos guarda-rios. Com a implementação do $\mathrm{RSH}$, foi criada a figura de guarda-rios, com competências muito vastas, dentro da sua área de intervençáo - o cantão, entre as quais, a polícia das águas, a interface com os utilizadores e a elaboraçáo de pareceres e informações de campo, sobre as diferentes propostas de utilização da água ou de alteração à rede hidrográfica. O engenheiro-chefe da 1ª Direcção dos Serviços Fluviais e Marítimos, frequentemente, reforçava a natureza dessa missão, como é o caso duma nota de serviço enviada ao chefe de conservação, em que recorda a necessidade dos guarda-rios em emitir "informaçóes e parecer no que respeita a determinadas obras e sobre possíveis prejuízos que estas podem causar aos chefes de conservação ou chefes interinos que depois transitam para o chefe de secção (acompanhados por desenhos e croquis).” De facto, os requerimentos foram sempre acompanhados duma folha de informaçáo, com um esquema explicativo do pedido solicitado, elaborado pelo respectivo guarda-rios (fig. 1).

Figura 1 - Exemplo de duas folhas de informação elaboradas pelos respectivos guarda-rios (1903 e 1971).

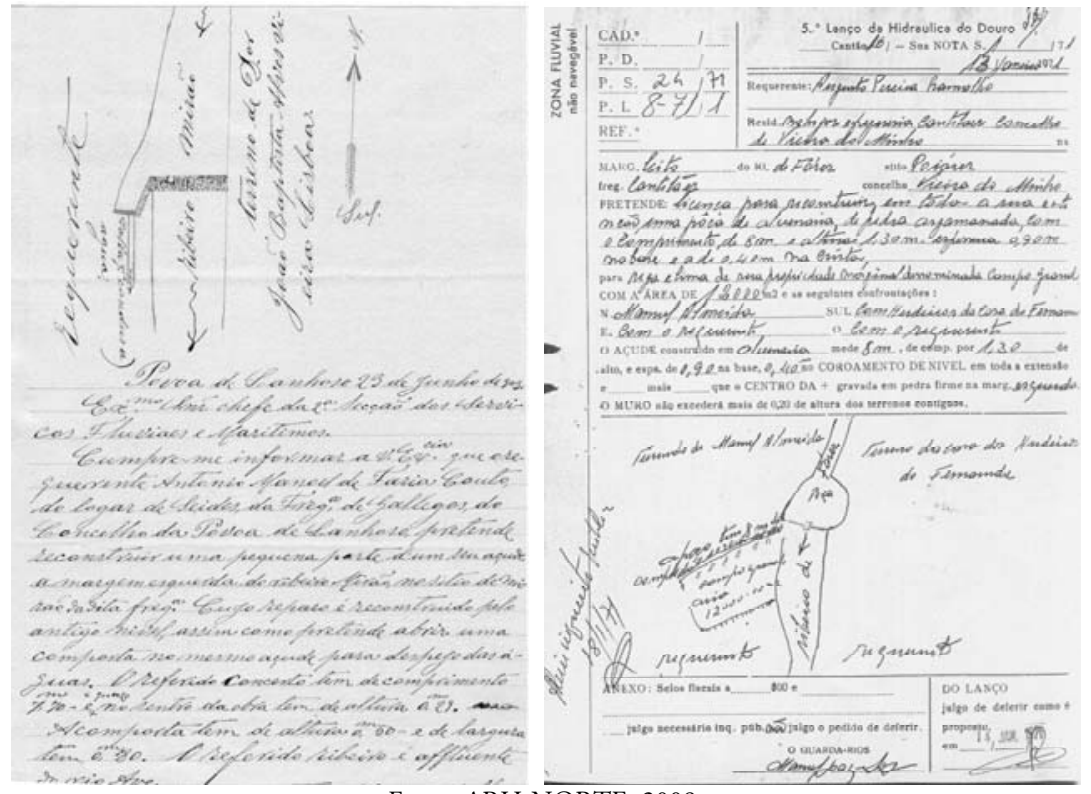

Fonte: ARH-NORTE, 2009.

Do ponto de vista legislativo, o RSH, na parte III relativa ao uso, policia e conservação das águas, margens, campos inundados e das obras neles executadas, refere no artigo 2070 que “ (...) O indivíduo, associaçáo, empresa ou corporação que pretender derivar águas (...) e utilizá-las, com o fim de interesse particular ou colectivo para (...) forca motriz (...) não o poderá fazer sem que obtenha a licença pelo Ministério das Obras Públicas, Comér- 
cio e Indústria, procedendo informação do director da respectiva circunscrição hidráulica e consulta do Conselho Superior de Obras Publicas e Minas." As licenças para obras permanentes ou temporárias nos cursos de água não navegáveis nem flutuáveis e nos seus álveos, leitos e campos inundados (caso do rio Ave), referidas no artigo $261^{\circ}$, ponto $3^{\circ}$ ("as plantaçóes ou execução de quaisquer obras, quer permanentes, quer temporárias (...) quando tiverem por fim o uso industrial das águas ou forem feitas por indivíduos não proprietários dos prédios confinantes com o curso de água, ou indivíduos proprietários de prédios confinantes, mas em localidades diferentes daquela onde se pretende construir as obras...”), eram concedidas pelos directores das circunscriçôes hidráulicas, quando delas não resultassem prejuízo de terceiros, ou ao regime da corrente e ao curso e escoamento das águas. Nos processos para a concessão destas licenças, era, em geral, exigida uma planta parcelar, em triplicado, numa escala nunca menor de 1 para 1000, do local onde se pretendia executar a obra, com todos os detalhes convenientes, e dos alçados, perfis e cortes necessários para fazer conhecer e apreciar a referida obra. Estas plantas compreendiam uma parte do curso de água a montante e jusante do local da obra, para se dar ideia do efeito da construçáo, sendo datadas e assinadas pelo requerente e seladas devidamente num dos exemplares.

\section{Licenciamento em Domínio Público Hídrico (DPH) - Alguns eXemplos de DOCUMENTOS CARTOGRÁFICOS}

São possíveis de identificar vários tipos de representações cartográficas associadas aos diferentes pedidos de licenciamento no DPH: plantas, perfis, cortes, alçados, esboços, croquis, esquemas e outros conforme são designados nos próprios documentos apresentados.

\section{ÁGUA E PRÁTICAS AGRÍCOLAS}

Os processos associados ao uso da água para a rega mostram um conjunto de documentos onde são visíveis as diversas técnicas de captação e os meios de extracção e derivação. As intervençôes sobre o leito na forma de açudes e barragens são as estruturas mais utilizadas (fig. 2).

$\mathrm{Na}$ maior parte das situaçóes referidas, a rega implicava um conjunto de obras e materiais, quer no leito, quer nas margens, de forma a permitir, além da captaçáo, a condução e o armazenamento da água, do curso de água para as propriedades a regar, nomeadamente, as não marginais. Tradicionalmente a condução era feita de forma subterrânea (fig. 3) ou ao nível do solo e podia recorrer a diferentes tipos de materiais e meios (tubo, cano de pesca e regos, levada...).

A colocação de estanca-rios nas margens para proceder a extracção de água por meio de poço também fazia parte dos pedidos dos requerentes (fig. 4), dado tratar-se dum meio de fácil construção.

Dos meios tradicionais de extracção, destacava-se também a utilização da roda copeira, frequentemente de tracção animal (fig. 5). 
Figura 2 - Projecto relativo ao pedido de licenciamento para construir barragem para rega

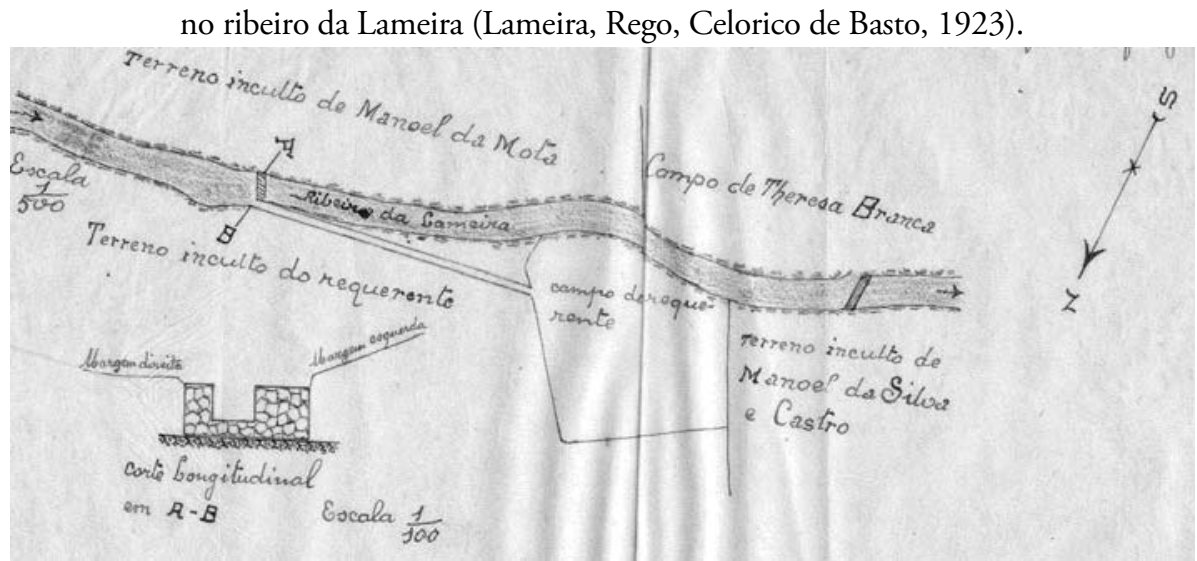

Fonte: ARH-NORTE, 2009.

Figura 3 - Projecto relativo ao pedido de licenciamento para extrair água do ribeiro de

Febras, destinada à irrigação (Rebelo, Caldelas, Guimarães, 1933).

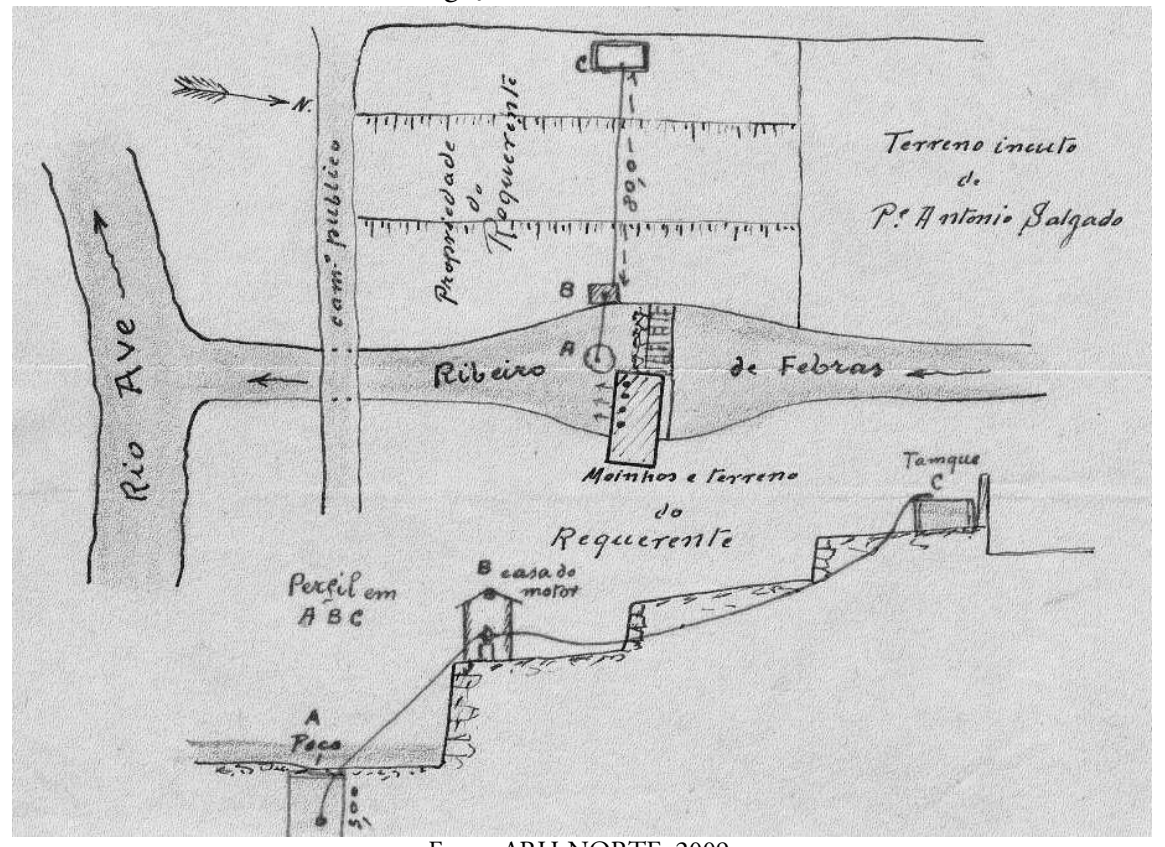

Fonte: ARH-NORTE, 2009.

As ramadas que ocupavam o Domínio Público Hídrico estavam também sujeitas à sua regulamentação. Frequentemente, as ramadas projectavam-se aereamente sobre o leito dos cursos de água estabelecendo os apoios nas respectivas margens (fig. 6), o que permitia desta forma não ocupar a área de cultivo. 
Figura 4 - Projecto relativo ao pedido de licenciamento para ligar uma mina por meio de cano destinado a derivar água do ribeiro de Covelas para alimentar engenho de rega

(Covelas, Santo Tirso, 1904).

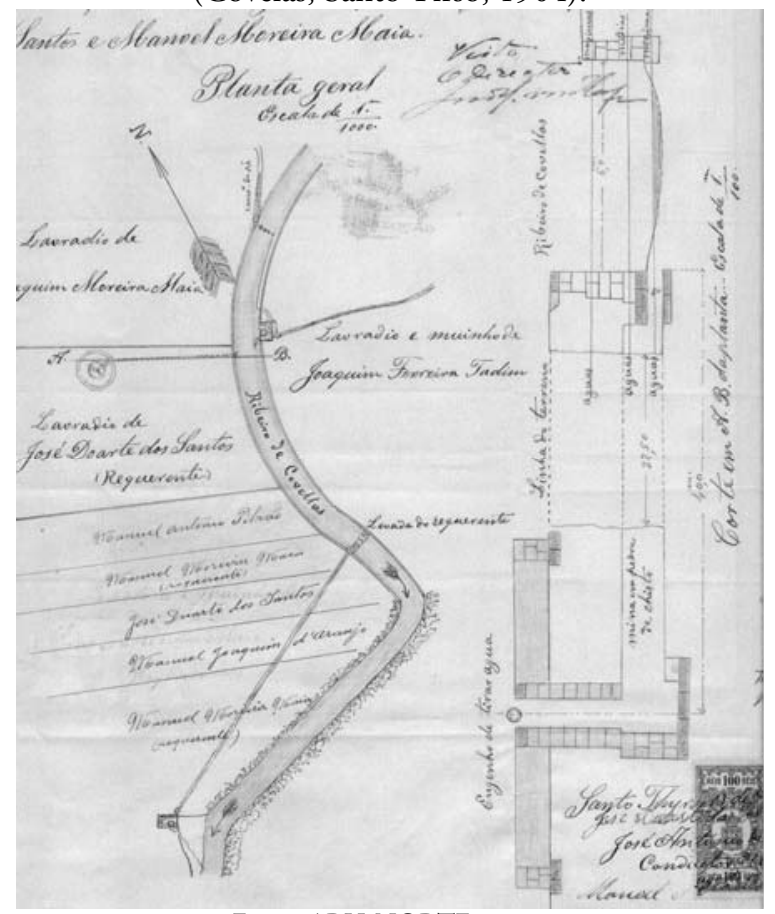

Fonte: ARH-NORTE, 2009.

Figura 5 - Projecto relativo ao pedido de licenciamento para construção de engenho de roda copeira de tracçáo animal, para extrair água do rio Este destinada à rega

(Bares, Rio Mau, Vila do Conde, 1940).

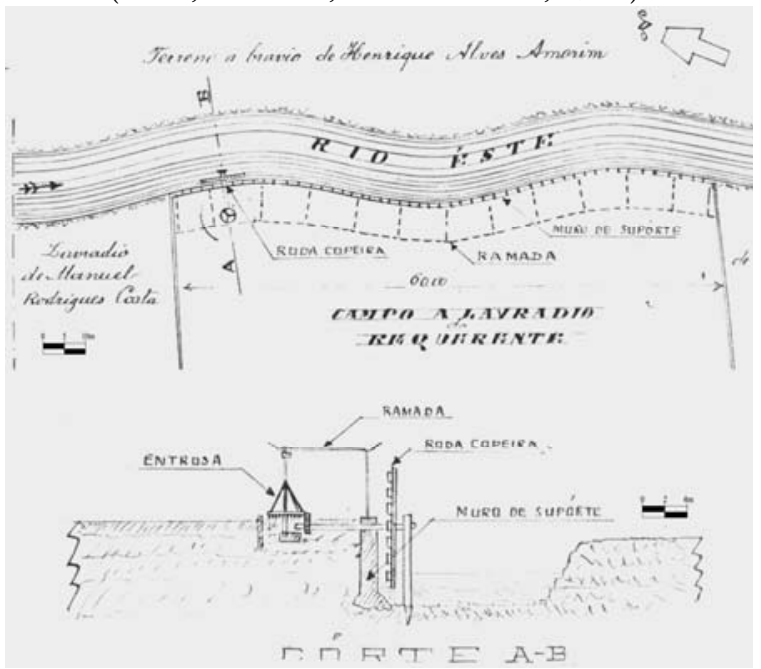

Fonte: ARH-NORTE, 2009. 
Figura 6 - Projecto relativo ao pedido de colocação de esteios de ramada sobre as margens do rio Pele (Landim, Vila Nova de Famalicão, 1905).

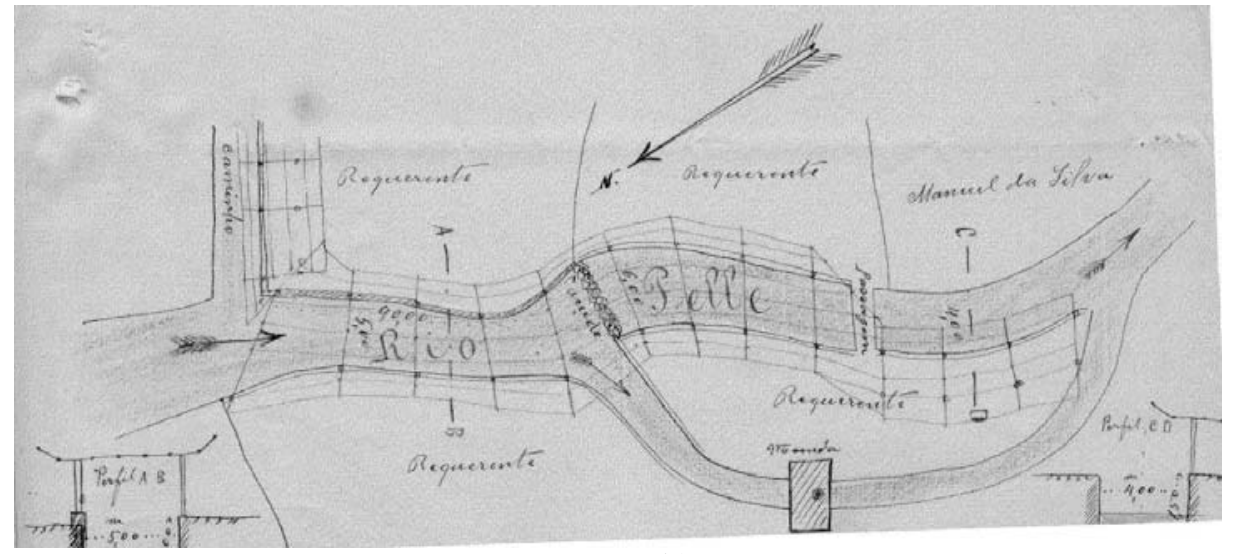

Fonte: ARH-NORTE, 2009.

\section{A ACTIVIDADE MOAGEIRA - DO APROVEITAMENTO HIDRÁULICO AO MOINHO}

O licenciamento para a construção de moinhos implicava um conjunto de procedimentos processuais bastante morosos. Era obrigatória a entrega de diversos documentos, nomeadamente uma planta, em triplicado, da parte do curso de água a montante e jusante do ponto onde iria ser feita a derivação, e as demais plantas, perfis, desenhos e esclarecimentos necessários a fim dos Serviços Hidráulicos avaliarem todas as circunstâncias da pretensão.

Os pedidos para a construção de moinhos e a reparaçáo dos existentes, ao nível do edifício (fig. 7) ou da sua estrutura hidráulica, eram frequentemente requeridos, dada a elevada representatividade desta actividade económica na bacia hidrográfica do rio Ave.

Figura 7 - Projecto relativo ao pedido de licenciamento para construção de casa de moinho, na margem direita do ribeiro de Atafona (Loureiro, Eira Vedra, Vieira do Minho, 1920).

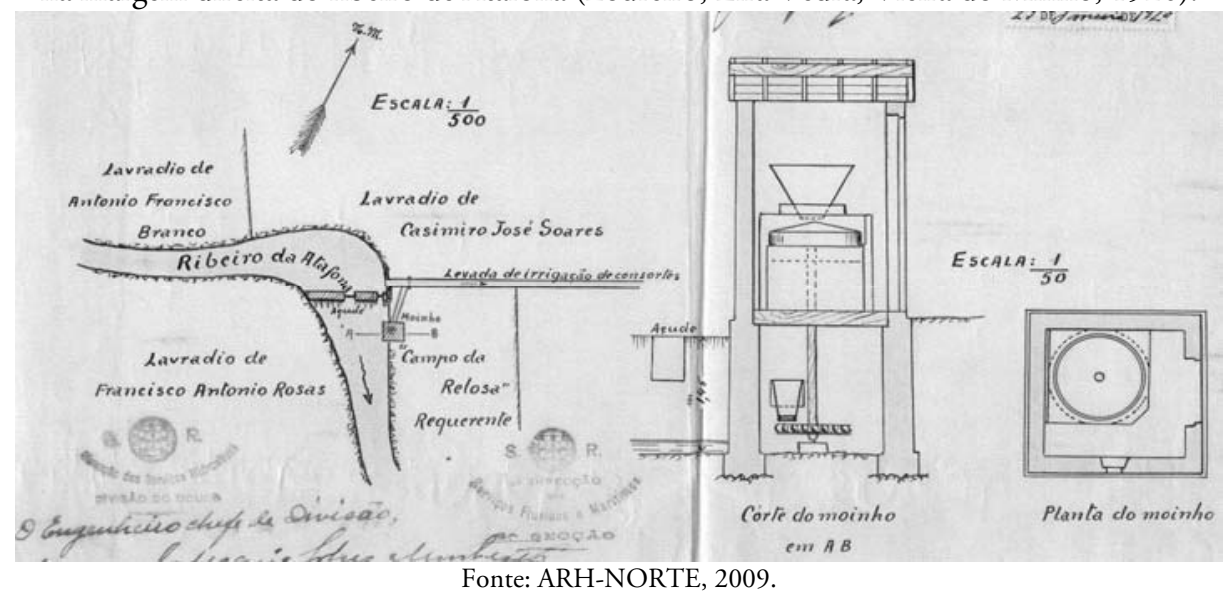


Os edifícios onde se implantavam os moinhos serviam diferentes processos de produção artesanal e industrial: a moagem de cereais (a mais comum), a serraçáo de madeiras e os lagares de azeite, que, por vezes, coexistiam complementarmente (fig. 8).

Figura 8 - Pedido de licenciamento para a construção de engenho de serrar madeira entre engenho de lagar e moinho, na margem direita do ribeiro de Figueiró

(Figueiró, Mosteiro, Vieira do Minho, 1920).

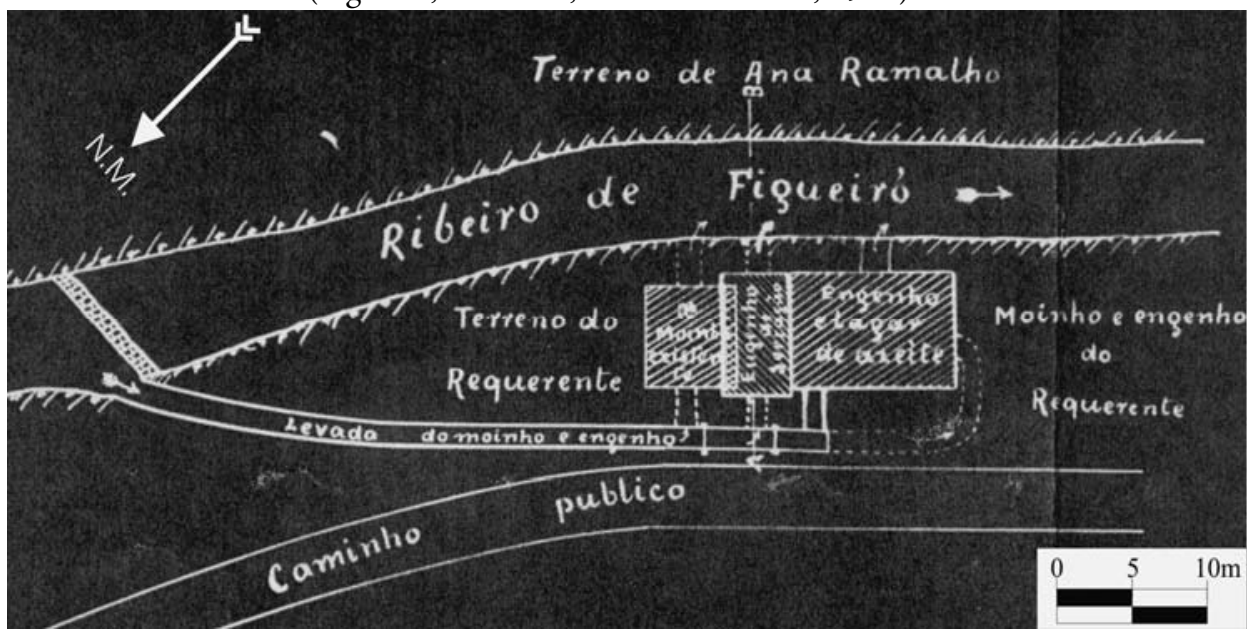

Fonte: ARH-NORTE, 2009.

\section{AS FÁBRICAS DE FIAÇÃO E TECIDOS - UMA RELAÇÃO HISTÓRICA COM O DOMÍNIO PÚBLICO} HÍDRICO

Ligadas ao processo de industrialização, encontramos a energia: hidráulica, aproveitada para fins industriais ou para a produção de energia eléctrica, o vapor e a electricidade. De facto, foi a esta forma de energia que recorreram as primeiras grandes fábricas que se instalaram no vale do Ave, as quais vieram a ter um papel pioneiro e inovador na industrialização da área.

O rio Ave e seus afluentes marcam, assim, a implantação industrial do têxtil, o que se relaciona com as vantagens associadas às facilidades hídricas para a produção de energia e abastecimento de água nas diferentes fases dos processos industriais em que esta é utilizada. Devido ao facto da água ser indispensável nas diversas fases do processo produtivo, nas lavagens e nas operaçóes de tinturaria, e na própria produção de energia motora, a "indústria mecânica" condiciona a localização das unidades fabris nas margens dos rios (fig. 9).

É neste quadro que se desenvolve um processo industrial historicamente sustentado pelo sector têxtil, onde é possível distinguir várias fases no que respeita à relação desta com o Domínio Público Hídrico. 
Figura 9 - Projecto relativo ao pedido de licenciamento para ampliar o edifício de fábrica de tecidos, destinado à tecelagem e a armazém de matérias-primas, na margem esquerda do rio Vizela (Sobre-o-Rego, Campo (Sáo Martinho), Santo Tirso, 1935).
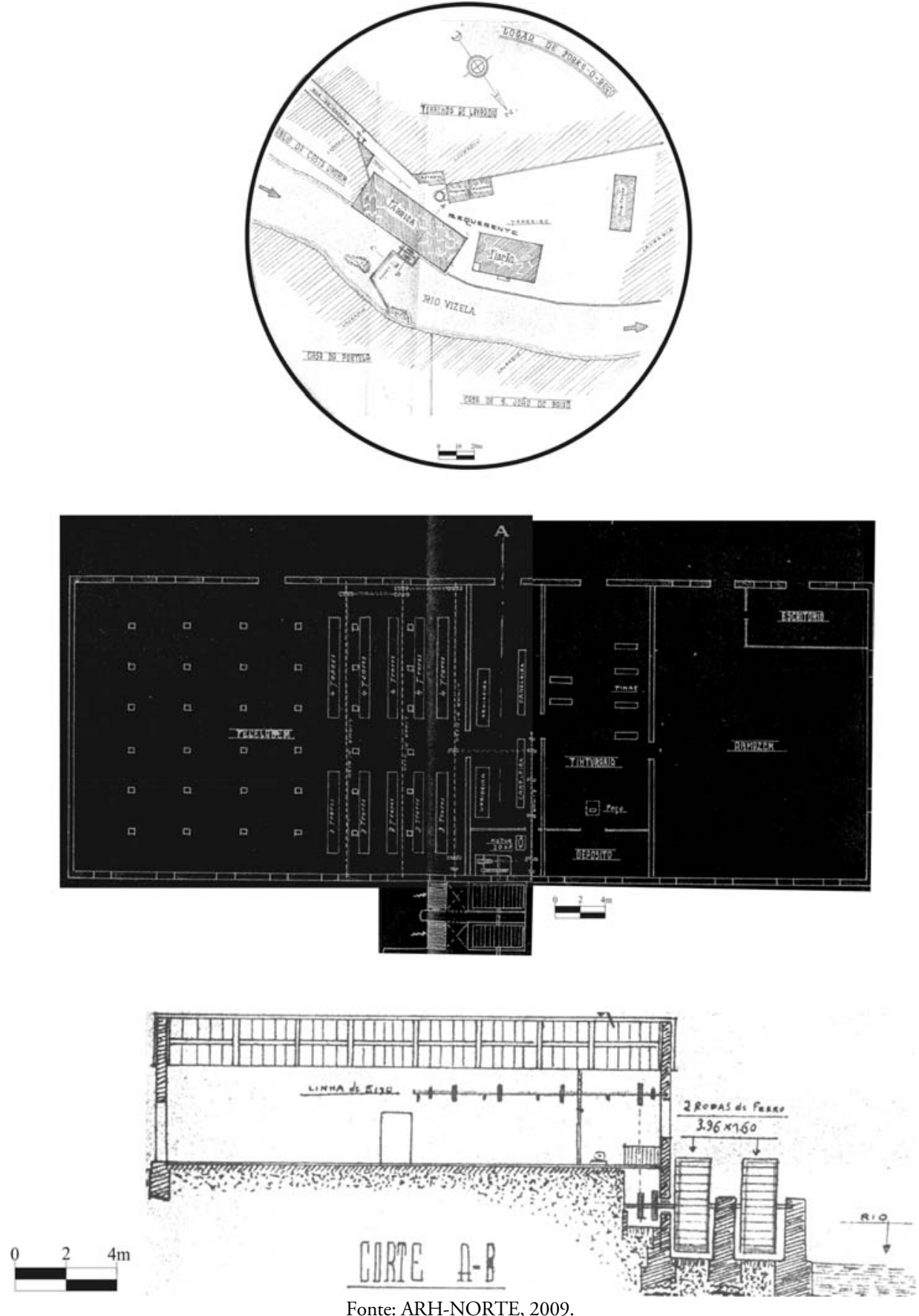


\section{CONSIDERAÇÓES FINAIS}

Tendo em conta a análise dos diferentes documentos gráficos e cartográficos que acompanham os processos de licenciamento na bacia hidrográfica do rio Ave, no período 1902-73, podemos apontar os seguintes aspectos positivos:

- a utilização da cor nos diferentes elementos representados, nomeadamente, a cor carmim para as estruturas físicas que vão ser intervencionadas;

- o pormenor de alguns cortes e perfis, nomeadamente, os relacionados com os aproveitamentos hidráulicos e os edifícios de implantação na sua relação com os cursos de água;

- a utilização de escalas diferenciadas que possibilitam uma boa visualização do pedido solicitado.

Também é de referir um conjunto de aspectos que dificultam a abordagem adequada às diferentes formas de expressão gráfica utilizadas:

- a falta de escalas, escalas inadequadas aos elementos representados e a utilização exclusiva das escalas numéricas (algumas vezes de difícil leitura);

- a falta de elementos de localização, quer relativa, quer absoluta, a utilização do norte magnético em detrimento do norte cartográfico e a confusão na utilização do norte geográfico;

- a utilização de diferentes planos de representação no mesmo desenho, em algumas plantas apresentadas;

- o desconhecimento dos responsáveis pelos desenhos incluídos nos processos.

Independentemente de algumas lacunas nas diferentes formas de representação apresentadas, os processos de licenciamento do DPH na bacia hidrográfica do rio Ave revelam imensos documentos de inestimável valor cartográficos.

\section{REFERÊNCIAS BIBLIOGRÁFICAS}

Costa, F.S. (2008). A gestão das águas públicas - O caso da Bacia Hidrográfica do rio Ave no período 1902-1973, Dissertação de doutoramento, Braga, 857 pp. 